\title{
The Politics and Poetics of Listening: Attending Headphone Verbatim Theatre in Post-Cronulla Australia $^{1}$
}

\author{
CAROLINE WAKE
}

This article analyses Stories of Love \& Hate, a headphone verbatim play produced in the aftermath of the Cronulla Riots in Sydney, Australia. While verbatim theatre typically invites audiences to listen therapeutically, Stories of Love \& Hate enacts and enables two alternative forms of listening. First, it enacts the paradoxical mode of 'ethical eavesdropping'; second, it enables the metatheatrical mode of 'mediatized listening'. In doing so, the play asks spectators to reconsider whom they listen to and how. It also asks scholars to reconsider claims that verbatim theatre gives voice to those who go unheard by the media. Instead, the article argues that in the case of Stories of Love \& Hate, headphone verbatim theatre enables the audience to listen to how the media listen.

We're more and more into communications and less and less into communication.

Studs Terkel

It's a nice line, usually attributed to the late, great radioman Studs Terkel, though he himself credits his contemporary, author and photographer Wright Morris. ${ }^{2}$ I first came across it in Anna Deavere Smith's book Talk to Me, where it appears twice, first in the following passage:

We are in a communications revolution. Yet, as ... Terkel tells us, 'We're more and more into communications and less and less into communication.' In this time of a global economy and business mergers ... where is the human merger? Where is real human engagement? ${ }^{3}$

The answer, for Smith, is theatre, or what Alan Read calls 'the last human venue'. ${ }^{4}$ Before I arrive at that venue in this article, I want to pause and consider this passage in more detail, because it hints at two key diagnoses that have been made in and of our time.

First, the mention of mergers hints at how neoliberalism has become an organizing principle not only for economics but also for politics and the polis more generally. Indeed, neoliberalism is now so embedded in political and social life that we only half-jokingly call a meeting a 'human merger'. This is how, according to sociologist Nick Couldry, neoliberalism has created a 'crisis of voice'. ${ }^{5}$ He argues that neoliberalism has no time for voice either as a process, since consulting with one's customers or constituents might slow one's rate of progress, or as a value, since the market is what determines anything or anyone's final worth. ${ }^{6}$ This has caused a sort of social laryngitis (my term, 
not his) whereby individuals and collectives inflame their throats not by shouting but by strangling their voices even before they emerge. The second diagnosis implicit in this passage is that the proliferation of 'communications', which I take to mean both broadcast and social media, does not so much help communication as hinder it. Here the argument seems to run thus: more platforms means more producers; more producers means more content; more content means more chaos, making it that much harder to discern the signal from the noise. In this way, Couldry's crisis of voice might also be described as a crisis of listening.

These are somewhat contradictory arguments: there cannot be too few voices at the same time as there are too many. Yet perhaps these trends are correlative rather than contradictory and it is precisely because there is a crisis of voice that voices are proliferating. This is political theorist Jodi Dean's argument in Democracy and Other Neoliberal Fantasies, where she contends that the intensive and extensive proliferation of media' has not, as supporters claim, led to increased participation in political life. On the contrary, it has produced what she calls 'communicative capitalism ... a politicaleconomic formation in which there is talk without response'. ${ }^{7}$ At best, communicative capitalism means that 'messages get lost'; at worst, it 'occludes the antagonism necessary for politics, multiplying antagonisms into myriad minor issues and events', making it all but impossible to mount a defence, let alone a counterattack, against neoliberalism. ${ }^{8}$

Faced with a media culture that is at once chaotic and conservative, the problem for theatre-makers becomes how to intervene in this public sphere without reproducing its structures. For those who make their work by soliciting stories, it means thinking about how to frame and perform these voices so that they sound like signals rather than simply add to the noise. This article investigates the problem, promise and paradox of a theatre that seeks to intervene in this media ecology by turning media's own tools against itself. More specifically, I consider Roslyn Oades's 'headphone verbatim' play Stories of Love \& Hate, as a performance that not only responds to a media event - the so-called 2005 Cronulla Riots in Sydney, Australia - but does so through media technologies. I argue that whereas verbatim theatre might bring 'voice to the voiceless', headphone verbatim theatre brings a reflexivity to proceedings that encourages the audience to contemplate how our culture of communication(s) is produced in the first place.

\section{Headphone verbatim theatre and audio-cued performance}

Stories of Love \& Hate is an example of what Oades calls 'headphone verbatim' and her English counterpart Alecky Blythe calls 'recorded delivery'. ${ }^{9}$ Since I am writing from and about Australia, and specifically about one of Oades's works, I will adopt the former term here. Like verbatim theatre, headphone verbatim theatre is

a form of theatre firmly predicated upon the taping ... of interviews done with 'ordinary' people, done in the context of research into a particular region, subject area, issue, event or combination of these things. This primary source is then transformed into a text which is acted, usually by the performers who collected the material in the first place. ${ }^{10}$ 


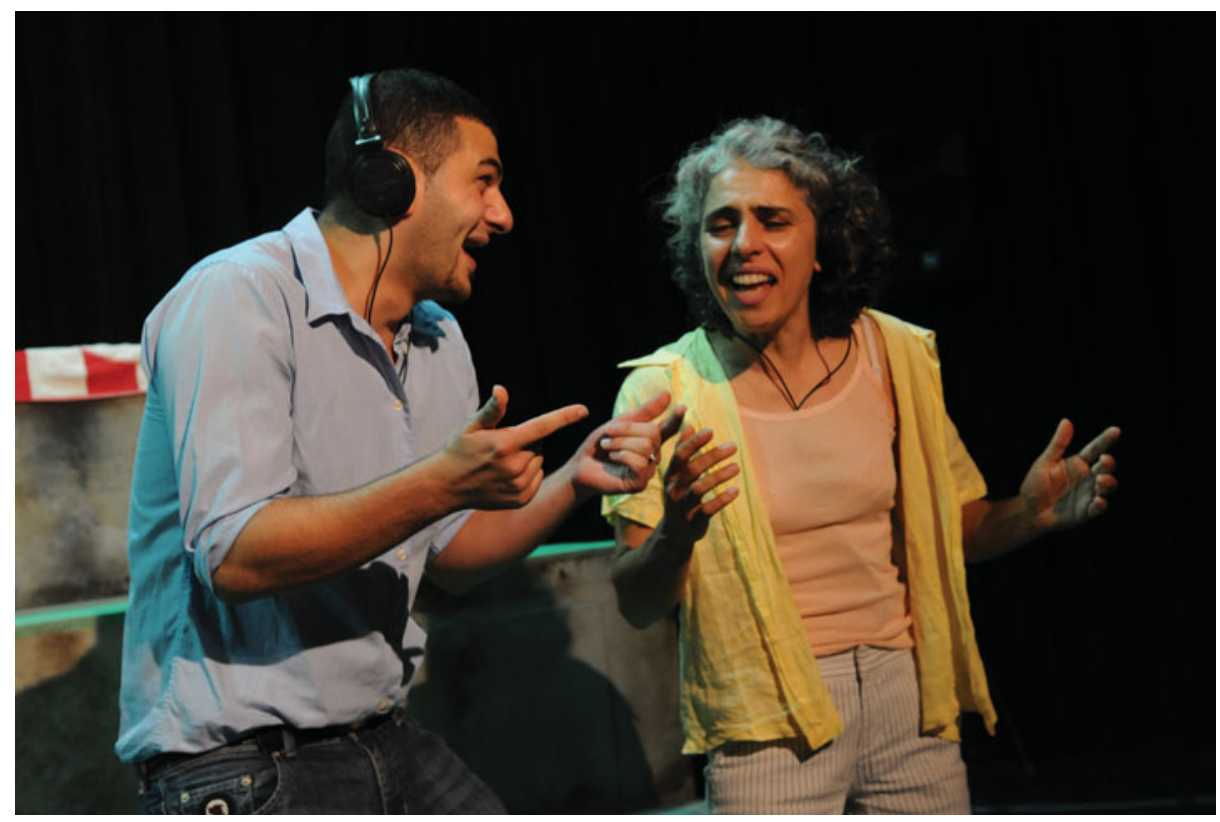

FIG 1 (Colour online) Mohammed Ahmad (left) and Katia Molino (right) as Moh D and Tommy. Photo credit: Heidrun Löhr.

Unlike verbatim theatre, however, headphone verbatim theatre brings its recording and playback devices out of the rehearsal room and onto the stage. In headphone verbatim theatre, actors perform wearing visible headphones, through which they receive what Oades calls an 'audio script' of the original interviews. ${ }^{11}$ The actors repeat this audio script as immediately and as accurately as possible, including every cough, stutter, pause, hesitation and repetition. The effect, according to audience members, 'is somewhere between acting, "being", and possession'. ${ }^{12}$

These terms hint at how, as I have argued elsewhere, headphone verbatim tends to be interpreted either as an attempt at absolute authenticity or as an alienation effect. ${ }^{13}$ However, more nuanced accounts recognize that alienation and authenticity are often working in tandem rather than opposition, meaning that verbatim theatre performs not so much authenticity as an 'aesthetic of authenticity'. ${ }^{14}$ Of course, the aesthetics of authenticity vary from show to show, but in most headphone verbatim plays the actors play several characters across several identity categories. In Stories of Love \& Hate, young Lebanese-Australian actor Mohammed Ahmad plays Ousama and Moh D, two young Lebanese-Australian men; Funda, a Lebanese-Australian schoolgirl; Max, a middle-aged Anglo-Australian man; Kirk, an Anglo-Australian surfer in his early twenties; and Courtney, a seventeen-year-old Anglo-Australian girl. Similarly, young Anglo-Australian actor Janie Gibson plays Mohammed A, a young Lebanese-Australian man; Nada, a Lebanese-Australian schoolgirl; Luke, an Anglo-Australian surfer in his late twenties; Jill, a seventy-nine-year-old Anglo-Australian; and Sam, a nineteen-year-old 
Anglo-Australian girl. In other words, they and their two cast-mates play up and down in age as well as with and against their gender and ethnicity.

While headphone verbatim can be seen as a subgenre of documentary theatre, it can also be interpreted as a type of 'audio-cued performance'. ${ }^{15}$ This genre takes in three categories of work: (1) performances in which the actors wear headphones but the spectators do not, (2) performances in which the spectators wear headphones but the actors do not, and (3) performances in which all participants wear headphones. Obviously headphone verbatim theatre falls into the first category, but so too does the work of the Wooster Group, as well as the work of their fellow New Yorkers, Nature Theater of Oklahoma. ${ }^{16}$ The second category is less familiar, but becoming more so thanks to performances such as Back to Back Theatre's small metal objects (2005). ${ }^{17}$ Finally, the third category of audio-cued performance seeks to dissolve the distinction between performer and spectator altogether, producing a hybrid 'performing spectator'. This category overlaps with what Christopher Balme calls 'audio theatre' and is dominated by audio tours and autoteatro works. ${ }^{18}$

Though a larger project on listening and audio-cued performance beckons, this article focuses on just one performance from one category. Through a close reading of Stories of Love \& Hate, I wish to pursue two related questions: first, what forms of listening does the performance stage? Second, how might listening, as both a practice and a theory, shift our understanding of documentary, verbatim and testimonial theatre? In order to consider these questions, I turn first to the events that the play depicts - the Cronulla Riots.

\section{The riots of the powerful}

The series of events that have come to be called the Cronulla Riots started on Sunday 4 December 2005, when three Anglo-Australian surf lifesavers confronted four young Lebanese-Australian men about their behaviour on Cronulla Beach, with insults and then punches being exchanged. This minor altercation became a major news story when the police issued a press release referring to men of 'Middle Eastern appearance', thus tapping into post-9/11 fears about the Arab and/or Muslim Other - the pre-eminent 'folk devil' of our time, as Scott Poynting et al. have argued. ${ }^{19}$ One radio shock jock labelled the men 'Middle Eastern grubs' ('grub' is Australian slang for 'a person with low moral standards, especially someone who contravenes an established code of behaviour ${ }^{20}$ ), while another called for a 'rally, a street march, call it what you will. A community show of force'. ${ }^{21}$ That same announcer also broadcast a text message that had been circulating in Cronulla and beyond, which said, 'This Sunday every Fucking Aussie in the shire [the Sutherland Shire, the local government area in which Cronulla is located], get down to North Cronulla to help support Leb and wog bashing day ... let's show them this is our beach and they're never welcome back'. ${ }^{22}$ Not to be outdone, Rupert Murdoch's tabloid Daily Telegraph and Fairfax Media's broadsheet Sydney Morning Herald also printed versions of this and other offensive text messages.

On the morning of Sunday 11 December 2005, a crowd assembled at Cronulla, as did various media organizations. The following newspaper account sets the scene: 


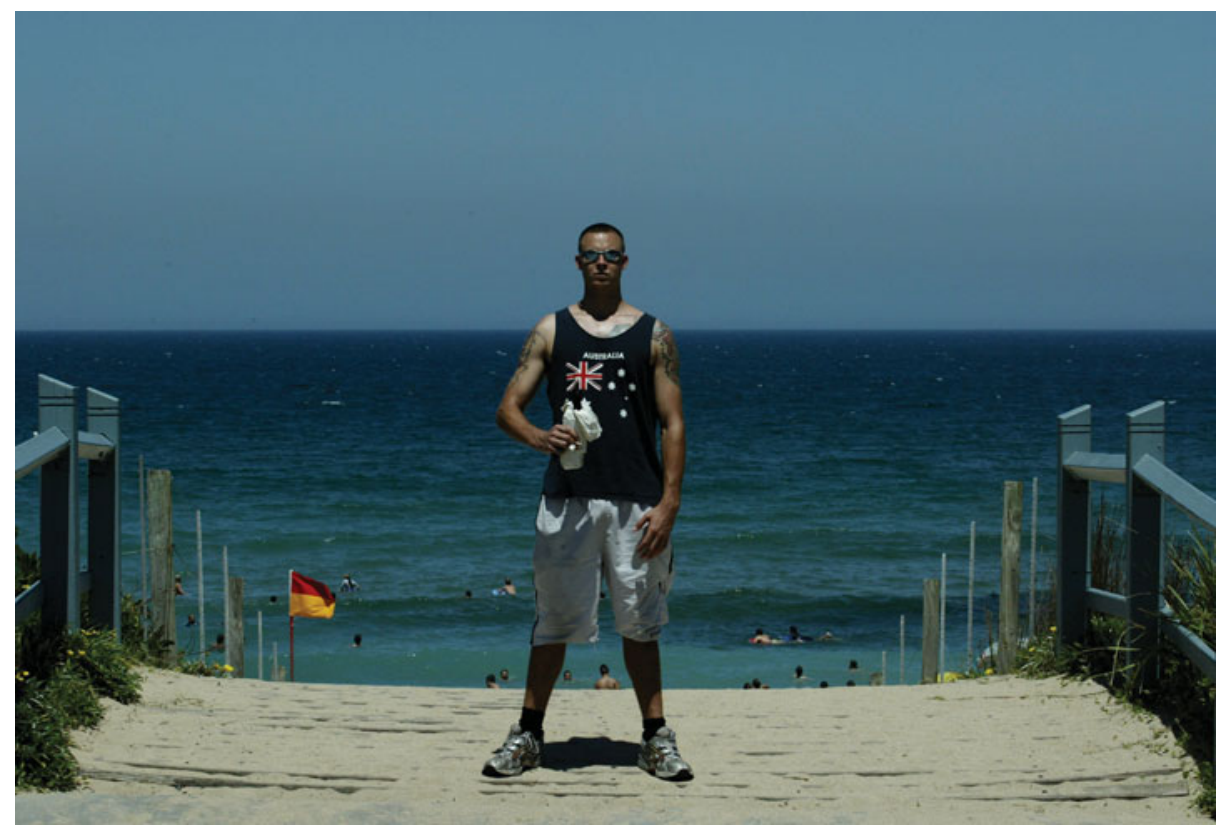

FIG 2 (Colour online) Two days prior to the Cronulla Riots, this image appeared on the front page of the Sydney Morning Herald where the caption read, 'Shaun Donohoe, 24, says he is angered by what he sees as an invasion of youths of Middle Eastern background on North Cronulla beach, 8 December 2005'. Photo credit: Andrew Meares.

A ute [utility vehicle] had a barbie [barbecue or mobile hot plate] on the back, its owner handing out free snags [sausages] and boxing kangaroo tattoos. Even dogs were wearing green and gold coats. The salty air oozed with patriotism ... But as the crowds grew, the clouds cleared, the day became hotter and the consumption of beer increased, the stench of racism became stifling. Chants of 'Lebs go home' and 'Aussie Aussie Aussie, Oi Oi Oi', warmed up the well lubricated crowd. ${ }^{23}$

Within hours, this performance of nationalism - a specifically and coercively AngloAustralian nationalism - had escalated into violence against anyone of 'non-Anglo' appearance. From 1 p.m. to 3 p.m., the crowd attacked several young men and women of apparently 'ethnic' backgrounds, before converging on the nearby train station. When two young men, again of 'Middle Eastern appearance', arrived at the station, the crowd started chanting racial abuse before scaling a fence and beating them. Finally a policeman, swinging his baton, rescued the young men.

That evening, around a hundred young Lebanese-Australian men from the Canterbury Bankstown area, a group of suburbs to the north-west of Cronulla, gathered at a local park in their area and formed a convoy of cars, converging on Cronulla. When they arrived they smashed cars and yelled through megaphones, challenging locals to come out and fight, though no one did. The police arrived almost immediately, breaking up the convoy and restoring order. Further reprisal attacks took place the following day 


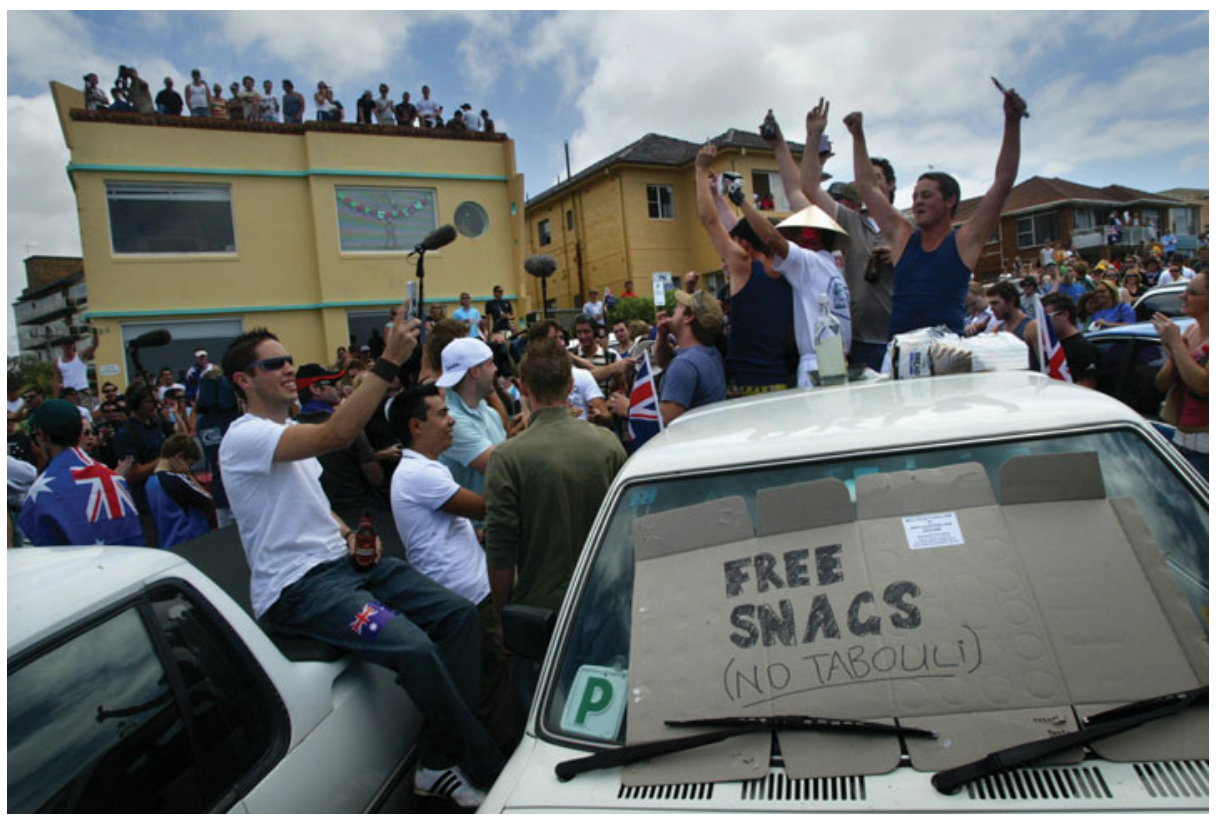

FIG 3 (Colour online) Anglo-Australian youths gather at Cronulla on 11 December 2005. Their car displays the sign 'Free Snags [sausages] (No Tabouli)', photo: Dean Sewell.

in neighbouring suburbs, before order was restored mid-week. Though the LebaneseAustralian crowd was roughly 2 per cent of the size of the Anglo-Australian mob, the reporting media focused on the former rather than the latter. ${ }^{24}$

These were not the riots of the powerless, then, but of the powerful. Poynting writes,

It was not a 'race riot' in the sense that we are used to in countries like the UK and France, where immigrant minorities are discriminated against until they reach breaking point, or the US, where the legacies of slavery and segregation spill on to the streets in violent outbursts after that latest 'last straw' ... The Cronulla riot was rather ... a violent attack by members of a dominant ethnic group against a minority, in order to put them back in their place. ${ }^{25}$

For this reason, some scholars argue that the events at Cronulla are better described as a pogrom rather than a riot. ${ }^{26}$ Either way, the ugly and enduring image was that of a privileged 'community that [nevertheless] felt victimised, gathering strength and expressing solidarity with itself ${ }^{27}$

In the aftermath of this social crisis all three levels of government mobilized: the Sutherland Shire and Bankstown City Councils implemented a variety of school and community programmes; the state government arrested, charged and convicted dozens of perpetrators; and the federal government's Australian Communications and Media Authority (ACMA) charged radio announcer Alan Jones with breaching the ACMA Code of Conduct. Together, all three levels of government ploughed millions of dollars into 


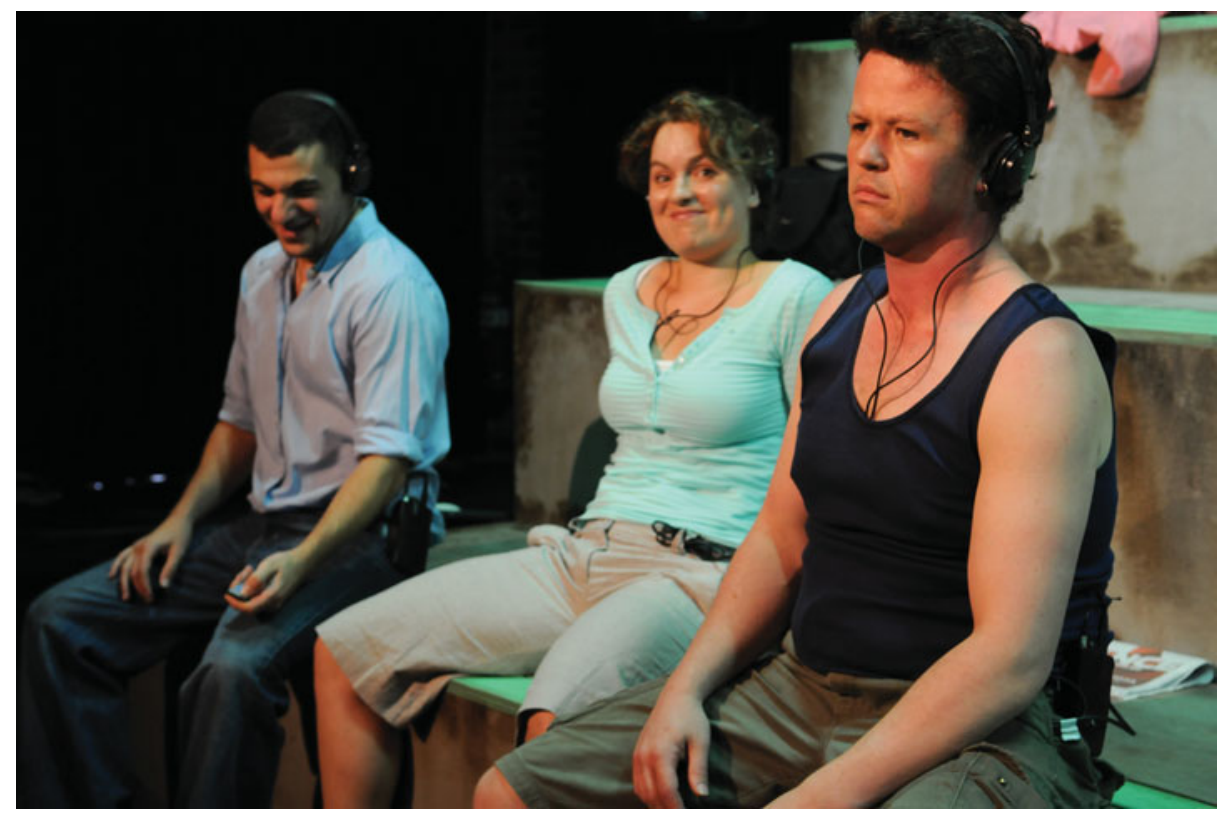

FIG 4 (Colour online) Mohammed Ahmad (left), Janie Gibson (centre) and Roderic Byrnes (right) as the Car Boys, Ousama, Mohammed A and Fred, in Stories of Love \& Hate, dir. Roslyn Oades. Photo credit: Heidrun Löhr.

social and cultural infrastructure. Though it might have happened anyway, since artists were always going to have to come to terms with the riots and what they meant for country and community, it was partly this funding strategy that ensured the emergence of the 'Cronulla Riot' play within the Australian repertoire. ${ }^{28}$

\section{Stories of Love \& Hate}

Stories of Love \& Hate was developed over two years by the Bankstown-based theatre company Urban Theatre Projects and the Bankstown Youth Development Service. ${ }^{29}$ In 2006, shortly after the riots, writer and director Roslyn Oades started working with communities in both Cronulla and Bankstown. ${ }^{30}$ As an Australian of Anglo-Celtic descent who grew up in Bankstown, a suburb where approximately 43 per cent of the population was born overseas and which is home for many Lebanese-Australians, Oades was in the unusual but ideal position of being able to win the trust of both communities. Like any ethnographer, she spent much of this early period just 'hanging out' with her informants. Later that year and throughout 2007, she interviewed more than sixty residents aged between fourteen and seventy-nine about their lives, loves and experiences of the riots. ${ }^{31}$ Over eighty hours of interview material was edited into a sixty-five-minute audio script for a play, comprising ten interlinking narratives. The play premiered in November 2008, spending one week at the Hazelhurst Regional Gallery, which is located one suburb over from Cronulla, and then another week at the Bankstown Arts Centre. ${ }^{32}$ 
The performance starts with Oades's voice, piped in over the loudspeaker. ${ }^{33}$ She can be heard double-checking her sound levels before asking a young man for his definition of love. He offers one before asking, rather endearingly, 'Is that right? Do you agree?'34 We also meet a middle-aged couple, whose love is such that he still buys her flowers: 'the other day', he says; 'the other month', she says simultaneously (8). For others, love is less about a person and more about an activity such as surfing - 'It's like being in the fallopian tube again I reckon' - or driving (13). One of the young men finds the sound of the bass literally heart-stopping - 'It's true!' he exclaims, 'you know you can die from bass?' (15). From here we segue into a radio programme called Love Song Dedications, where a honey-voiced host - the Love God - takes calls from the public and plays their favourite love songs.

Having circled around the topic of love, the play slowly spirals inwards towards issues of hate and eventually to the events themselves, a structure that is reminiscent of Anna Deavere Smith's Fires in the Mirror, another oral-history play about a riot. Intriguingly, divisions emerge within communities as well as between them. One character is careful to point out that Punchbowl is no Mount Druitt, though both are located in Sydney's western suburbs (19), and three young Lebanese-Australian men jokingly refer to their 'ghetto' and debate whether or not they are 'Lebanese', 'wogs', 'Middle-Easterns', 'Middle-Eastern Australians' (33), or 'Middle-Eastern wogs' (42). Likewise, the surfers are dismissive of those who have tattoos of the Southern Cross - the constellation that dominates Australia's sky and flag - which 'mean nothing', whereas they themselves have scars that tell 'ridiculous stories' (22). When the discussion finally moves to the day of the riot, the surfers insist that there were hardly any locals at the scene, that it was mainly '[kanga]roo shooters' and 'Romper Stompers', a reference to a Russell Crowe film in which he plays a neo-Nazi (38). Whoever was at Cronulla, though, was intent on violence, as a policeman and a photographer reveal. The flower-giving husband is revealed to be the baton-wielding policeman who saved the two men who were being beaten on the train. So shocked is the photographer by the ferocity of these attacks he witnessed that he says simply, 'I put the camera down. I put it down' (40).

In the final scene, we hear the recording of an older woman as well as Molino's repetition of it. Inevitably they are not the same and this not only serves as a metatheatrical reminder about the nature of repetition and remediation but also makes visible the invisible labour of listening. The play closes with the sound of bottles breaking and the crowd chanting.

\section{Ethical eavesdropping}

Perhaps the most habitual way of listening to verbatim theatre is 'therapeutic listening', as audio cultures scholar John Tebbutt calls it in a slightly different context. ${ }^{35}$ Therapeutic listening borrows from psychoanalysis, positing listening as a 'cure' and positioning the spectator as a secondary witness, which is to say as someone who listens to testimony or stories of trauma, violence and violation. The assumption is that through listening to testimony, the spectator, like the therapist, will 'com[e] to feel the bewilderment, injury, 
confusion, dread, and conflicts that the trauma victim feels'. ${ }^{36}$ Though it can work, there are at least three risks associated with therapeutic listening. Most obviously, the model does not always take into account how private listening in the consultation room might differ from the public listening that happens in and through performance. The second risk of therapeutic listening is, as theatre scholar and playwright Julie Salverson has noted, that we tend to listen for injury and violation rather than resistance, hope, humour and resilience. ${ }^{37}$ Consequently, performance risks perpetuating what Salverson has termed an 'aesthetic of injury', an aesthetic which valorizes the victim, sentimentalizes those with little power and stages a 'reduced version of "the tragic" which does not account for the complexities, contexts and strengths of those who are injured by injustice'. ${ }^{38}$ This risks solidifying existing social arrangements, meaning that therapeutic listening comes dangerously close to 'conservative listening', or what Justine Lloyd has called 'listening for disturbance (without being disturbed)'. 39

Stories of Love \& Hate avoids the aesthetic of injury for several reasons. First, rather than confronting the Cronulla Riots directly, Oades comes at the issue obliquely, stating in her programme note that the play 'is not a work about the riots, but rather a work about the ordinary people who were there'. ${ }^{40}$ Second, instead of charting the 'post-traumatic' aftermath of the riots, the performance focuses almost entirely on the 'pre-traumatic' context by asking characters about their loves and lives prior to the riots. In addition, Stories of Love \& Hate includes interviews with the perpetrators as well as the victims and bystanders, thus complicating lines of identification and preventing audience members from identifying simply as, or solely with, the victims. Third, and most intriguingly, Stories of Love \& Hate steers the audience away from therapeutic listening because it offers several other forms of listening, including what I call 'ethical eavesdropping'.

While there are some scenes in which a single actor addresses the audience, for the most part the characters address us in groups of two, three or even four. When watching these group scenes, it is hard to listen therapeutically. In fact, it can be hard to listen at all as conversations split, double, converge, pause, restart and split again. Even readers of the script may struggle, as this scene between three Lebanese-Australian schoolgirls illustrates. The script is formatted in two columns, in order to represent simultaneous speech, while the slash symbol (/) represents an interruption:

\begin{tabular}{|c|c|}
\hline $\begin{array}{l}\text { FUNDA: 'Cuz if you hit one Lebo- /-the whole } \\
\text { All of their cousins will come, and } \\
\text { their cousins will call their cousins }\end{array}$ & NADIA: Oh mate, you done a mistake. \\
\hline $\begin{array}{l}\text { NADA: Yeah, even if they don't know you, } \\
\text { they're gonna come to support you- }\end{array}$ & $\begin{array}{l}\text { NADIA: you made a mistake, /Or like, } \\
\text { you touch someone's sister, oh mate, } \\
\text { you've made the biggest mistake ever. } \\
\text { They will just come, and (laughing) } \\
\text { attack you and they will never leave } \\
\text { you alone. }\end{array}$ \\
\hline
\end{tabular}

FUNDA: You have a fight with one, a dozen comes. (45) 


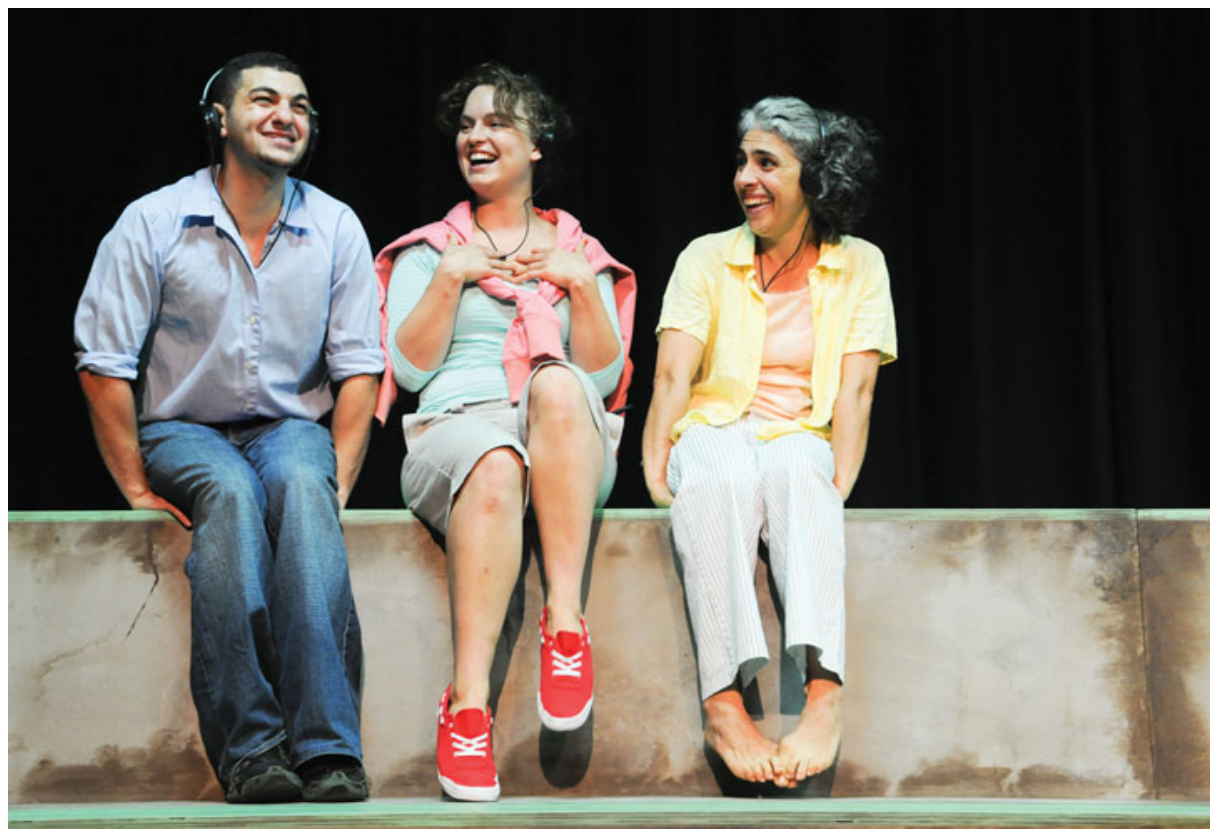

FIG 5 (Colour online) Mohammed Ahmad (left), Janie Gibson (centre) and Katia Molino (right) as the Auburn Girls, Funda, Nada and Nadia, in Stories of Love \& Hate, dir. Roslyn Oades. Photo credit: Heidrun Löhr.

There are few analyses of group scenes in the discourse on verbatim theatre, partly because such scenes are relatively rare in the form. One of the most detailed discussions occurs in feminist theatre scholar Jill Dolan's Utopia in Performance, where she gives an account of two group scenes in a production of The Laramie Project. Dolan states that the director 'positioned the actors to listen closely and visibly to each other, staging their interactions in groups of pairs of people talking together, which demonstrated the attentiveness the production sought from its audience'. ${ }^{41}$ Actors not directly involved in a scene remained onstage and 'watched each other perform and listened empathetically'. ${ }^{42}$ In doing so, according to Dolan, the production positioned the actors as 'model listeners', who both represented and 'create[d] a new public of attentive listeners'. ${ }^{43}$ But what happens when characters do not listen closely to each other, and are instead distracted, unfocused, scattered and sometimes rude? Or when the actors appear to be listening more closely to the headphones than to each other? What sort of listening is this and where does it leave the spectator? Such scenes, I argue, symbolize and facilitate a form of listening better known as eavesdropping.

In his book Performing History, theatre scholar Freddie Rokem theorizes eavesdropping as a form of 'secre[t] witnessing' ${ }^{44}$ Eavesdropping can occur in one of two ways: (1) in what he calls 'screen-scenes' where one of the 'characters is secretly spying on one or several of the other characters', and (2) when a character 'intentionally takes a position outside the direct action'. ${ }^{45}$ In Stories of Love \& Hate, however, a third way 


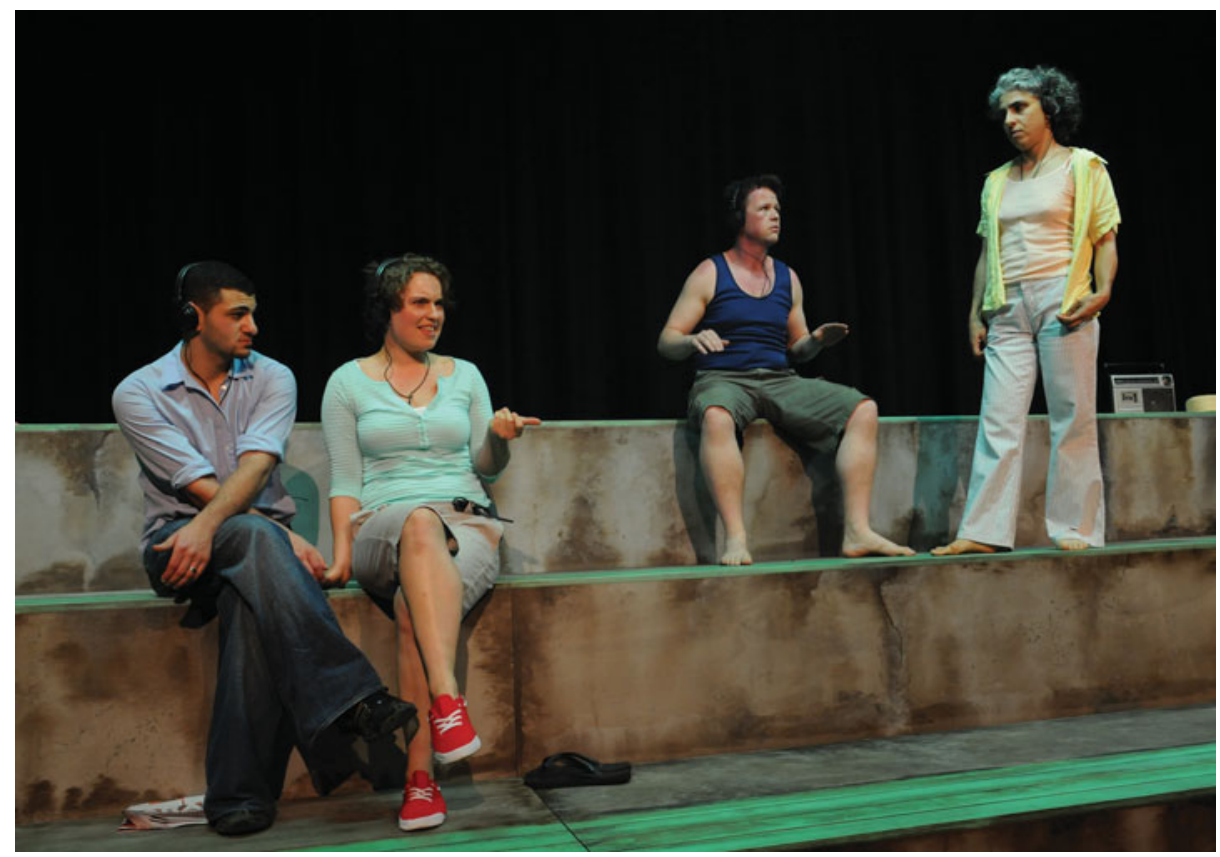

FIG 6 (Colour online) Mohammed Ahmad (left), Janie Gibson (centre left), Roderic Byrnes (centre right) and Katia Molino (right) perform eavesdropping - tuning in and out of each other's conversation as the Shire Kids, Courtney, Sam, Tini and Emily, in Stories of Love \& Hate, dir. Roslyn Oades. Photo credit: Heidrun Löhr.

appears, as none of the characters are secretly spying on the others, nor do any of them take a position outside the action, though they do drift in and out of the conversation. Instead, they appear to address an interviewer who is never represented onstage and whom they apparently forget about as they wander, flirt and guffaw their way through their various conversations. It is not merely that the interviewer is not staged; it is as if she is simply - though momentarily - not there.

This is where Rokem's theory of eavesdropping might be usefully supplemented by that of rhetorician Krista Ratcliffe. In Rhetorical Listening: Identification, Gender, Whiteness, Ratcliffe moves away from the common understanding of eavesdropping as the practice of 'listening secretly' and recovers other etymologies, finding

Old English etymologies of eaves suggesting 'edge' and 'margin' and 'border' ... an archaic definition of eavesdropping suggesting 'to learn or overhear' ... [and] a Middle English definition of eavesdropper suggesting 'one who stands on the eavesdrop [the spot where water drops from the eaves] in order to listen to conversations inside the house'. ${ }^{46}$

Here eavesdropping emerges as a composite practice of 'choosing to stand outside ... in an uncomfortable spot ... on the border of knowing and not knowing ... granting 


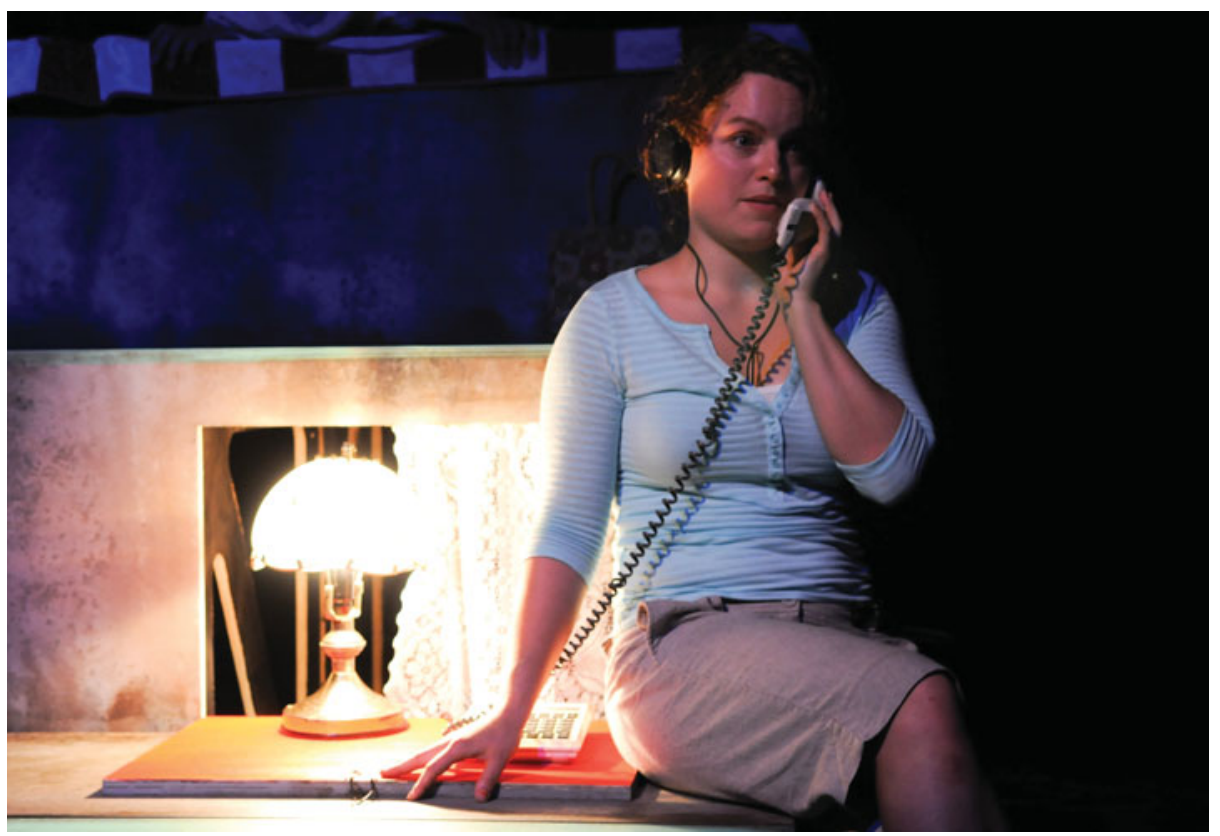

FIG 7 (Colour online) Janie Gibson as Monique performs mediatized listening - wearing headphones while making a phone call to request that Whitney Houston's 'I Will Always Love You' be played on the radio, in Stories of Love \& Hate, dir. Roslyn Oades. Photo credit: Heidrun Löhr.

others the inside position ... listening to learn'. ${ }^{47}$ It becomes a method of 'purposely positioning oneself on the edge of one's knowing so as to overhear and learn from others' and thus, according to Ratcliffe, a way of listening cross-culturally. ${ }^{48}$

When asked for real-life examples, Ratcliffe suggests that we can eavesdrop by listening to our students talk before class, by reading a scholarly text on an unfamiliar subject, or by viewing an advertisement for a political candidate we dislike and trying to 'heed why its addressed audience finds it so compelling'. ${ }^{49}$ In this way, 'eavesdropping enhances critical thinking'. ${ }^{50}$ Yet thinking critically does not mean thinking contemptuously and Ratcliffe cautions that 'eavesdropping demands an accompanying ethic of care'. ${ }^{1}$ Sociologist Tanja Dreher has argued that more than 'care', eavesdroppers need permission from those they are observing. Dreher, a 'white, middleclass woman', describes her experience of organizing but not speaking at a symposium for Indigenous and Muslim feminists as an instance of 'eavesdropping with permission', and offers it as a methodology for cultural studies more broadly. ${ }^{52}$

Through her interviewing practice Oades has created the conditions in which she is granted implicit and explicit permission to eavesdrop: implicitly, through her longterm presence in her subjects' lives; explicitly, through her practice of giving them her phone number, sending them a copy of the interview, getting them to sign a release form, allowing them to withdraw from the process within one week of the interview and allowing them to remain anonymous if they prefer. ${ }^{53}$ Through her, the audience, too, is 


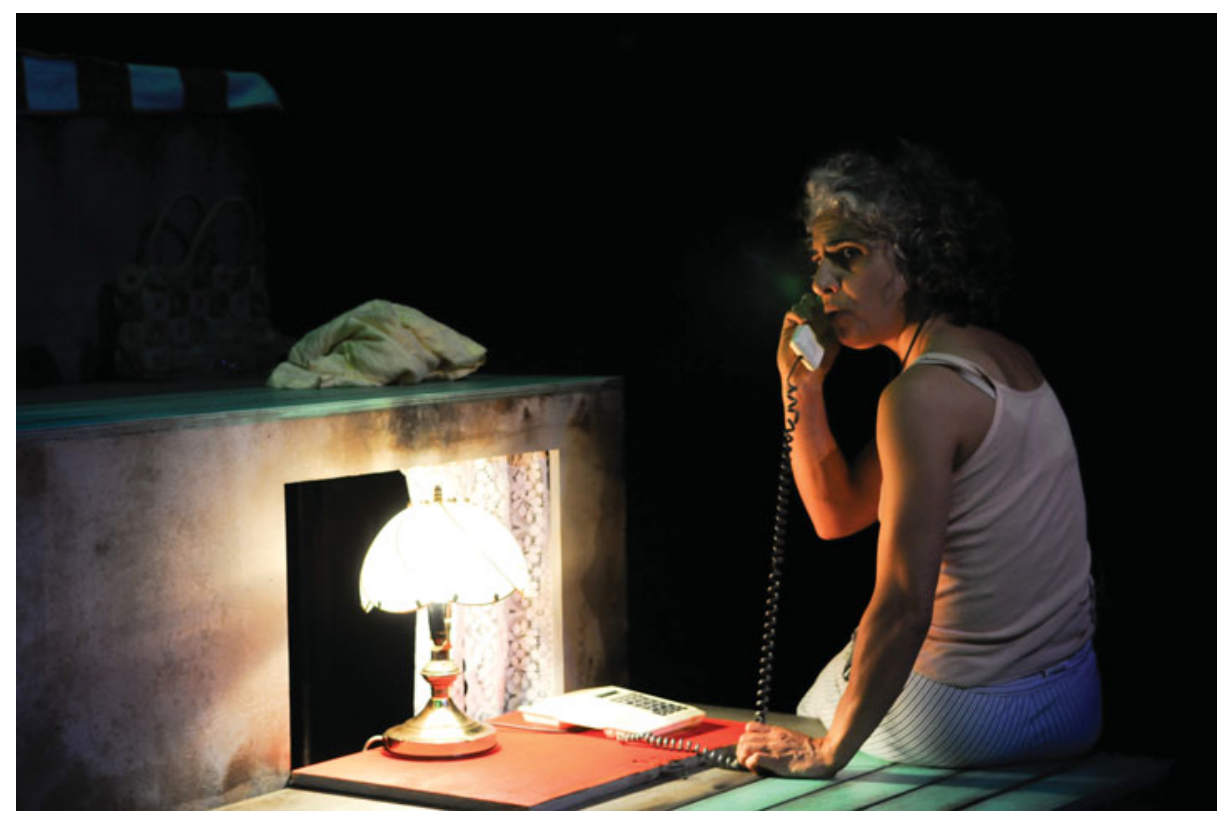

FIG 8 (Colour online) Katia Molino as Houda performs mediatized listening - wearing headphones while making a phone call to request that Diana Ross and Lionel Ritchie's 'Endless Love' be played on the radio, in Stories of Love \& Hate, dir. Roslyn Oades. Photo credit: Heidrun Löhr.

granted permission to eavesdrop on communities to which we would not normally have access. Though I am a Sydneysider, I rarely go to either Cronulla or Bankstown. Even if I did, I would not necessarily have much in common with the Cronulla schoolgirl who has a Southern Cross tattooed on her shoulder or with the three Bankstown boys who spend thousands of dollars on imported engines for their cars. Both of these worlds are equally foreign to me, and yet through Stories of Love \& Hate I am able to hear them not only talking, but talking among themselves. In this way, the performance creates a public space for the apparently paradoxical practice of 'ethical eavesdropping' where in contrast to Rokem's secret listeners - we are visible as eavesdroppers.

\section{Mediatized listening}

Interspersed with these group scenes are three scenes in which single characters call a radio station to dedicate a song to a current or former lover. When I first reviewed the play, I found these scenes 'a touch contrived and too close to parody'. ${ }^{54}$ On reflection, however, I have come to appreciate the many other modes of listening modelled in these encounters. Of course, it is arguable that they simply offer another opportunity to eavesdrop, albeit in a slightly different way. This reading is encouraged by the mise en scène, which places the performers on either side of the stage and has them address the blue night air that hangs between them rather than the audience or each other. In addition, the actors are often positioned in profile or with their back to the audience, 
enhancing the sense that they are saying something private. This would seem to confirm Ratcliffe and Dreher's shared conviction that 'listening in' to media is another way of eavesdropping with curiosity, care and implicit permission.

Yet theories of eavesdropping do not fully account for what is happening here, especially in the striking moments where the actors are listening to the phone while still wearing their headphones. On the one hand, the caller appears isolated by media technologies, particularly the headphones, thus confirming cultural suspicions that they manifest 'a refusal of public exchange and [an] apparent regression to individual solitude'. ${ }^{55}$ This isolation is increased by the staging, which places the actors on either side of the stage with minimal lighting. On the other hand, and contrary to our expectations, perhaps, the radio host models a patient and empathetic listening. For example, when Monique calls to dedicate a song to her boyfriend Adam, who proposed yesterday and is apparently still waiting for an answer, she stammers that she's 'got a lot going on at the moment, family dramas and just, you know things like that', adding, 'I feel terrible an' I jus- I hate myself, but I just don't know what else. Um, I don't, I-' (16-17). In response, the character of the Love God summarizes the situation with great tact, saying,

Understood. You, you're being honest with Adam and you're saying that, that type of commitment at this stage is something you can't even entertain ... Understood. Well I, I hope that Adam appreciates your honesty, and ... ahh, is it going to change things between you two from the point of view that he is still the main man in your life? (17)

When she replies that it isn't, he says, 'Alright, so, we're delivering that news to Adam, which I'm sure he probably doesn't want to hear, but at least he would know that he still has your love' (17). He announces 'This is for you Adam' and the opening phrase of Whitney Houston's 'I Will Always Love You' plays (17). Similarly, when Houda calls and asks to dedicate Diana Ross and Lionel Ritchie's 'Endless Love' to her ex-husband, the Love God says gently, 'Ohh, this is a lost love for you?', before asking how long they have been separated and how the intervening months have been. Unlike many in the audience, he does not laugh at her bitter and ironic song choice or do anything else to dismiss her pain. Instead, he simply thanks her for calling and announces, 'This is for you Khaled' (42).

There is no doubt that the listening of the Love God resembles therapeutic listening, but because it plays out through media it is never only that. Instead, these scenes produce a mode that I call 'mediatized listening' whereby spectators can see how media industries, media technologies and media practices intersect and diverge. Such scenes remind us that media technologies and practices are not one and the same and that neither is synonymous with the mainstream media. They also complicate the conventional wisdom that verbatim theatre employs media technologies in order to rescue stories that media industries neglect, ${ }^{56}$ for here it is the technology that seems to isolate and the industry that seems to include, as the Love God listens to modest people telling their modest stories. Indeed, his very presence underlines the fact that Stories of Love \& Hate is responding to an event that even those of us who live in Sydney experienced as a media event.

The mutual imbrication of life, media and performance is most clearly illustrated in the scenes where the characters themselves sing their favourite songs. In one scene, 
Noelene and Jill demonstrate how they sing 'Oh What a Beautiful Morning!' together when they arrive at the ocean baths for their daily swim. Later in the play, Noelene sings 'I Wouldn't Trade You for the World' about her husband (46-7). In another scene, Tommy and Moh D chortle that their favourite love song is 'Sexual Healing' (35-6). In the scene immediately after that, arguably the climax of the play, the characters Emily, Tini, Sam and Courtney nominate 'Under the Bridge' by the Red Hot Chilli Peppers as their favourite love song (36). They start singing it, before pulling out a phone on which they have footage of themselves drinking and dancing to the song. When Emily presses 'play', the recorded song swamps the space and we are transported back to the party, as the actors jump around while holding onto their headphones.

Perhaps rather than telling stories that the media misses, headphone verbatim theatre enables spectators to listen to how the media listens. It also encourages us to reflect on how we, as audience members, listen to and through media. In other words, watching this type of audio-cued performance facilitates a sort of meta-listening. More radically, if there are journalists in the audience, it may even 'help [them] to help themselves to listen'; that is, to stop doing what Nadyat El-Gawley calls 'listening out' (for a particular statement from a politician or spokesperson that can be incorporated easily into an article) and to start simply listening. ${ }^{57}$ Regardless of our profession, these scenes reinforce the fact that performance and media are not separate spheres but rather part of the fabric of life itself.

\section{The limits of listening}

There are, of course, limits to what listening, as both a practice and a theory, can achieve. Indeed these limits are inscribed within the form of headphone verbatim itself, since the actors cannot listen to the audience as attentively as they might without headphones. Furthermore, once the audio script has started there is no way to alter its timing, meaning that actors cannot adjust their performance in any way, for example by pausing for a laugh line. This sort of listening without pause recalls politicians' 'listening tours', as well as managerial strategies of 'listening' to your employees before doing what you were going to do anyway. These examples, as Lloyd has argued, prove that listening is not infallible and that it is easily coopted. ${ }^{58}$ Finally, we have to remember that listening rarely operates alone - we are usually looking and listening simultaneously, so that even if a performance models a new form of listening, it may perpetuate old spectatorial habits.

Nonetheless, listening still might provide new ways in which to theorize political, theatrical and testimonial publics. Theories of eavesdropping, for instance, invite us to think further about the similarities and differences between accidental eavesdropping, such as overhearing someone answer their phone in public, and deliberate eavesdropping, through espionage and state surveillance. How do such practices assist, damage or disable the formation of publics? Likewise, theories of mediatized listening encourage us to consider how the media themselves both enable and block listening within and between publics. Theatre scholar Alice Rayner's recovery of the archaic meaning of audience, as in 'to grant an audience', also encourages subjects to contemplate who it is that they listen to. ${ }^{59}$ Rather than thinking about whether the subaltern can speak, listening encourages 
us to think about whether the mainstream subject can listen. For me, because I am, like Dreher, a white, middle-class woman, this means asking myself, how do I listen? To whom do I listen? And when was the last time I really listened? More broadly, theories of listening might also help to reformulate such historiographical questions as 'why weren't we told?' into 'why couldn't they listen?' 60

When I asked Mohammed Ahmad in the foyer about what it is like to act in these plays where there is little room for error, he replied, 'It is not enough to listen word for word; you have to listen breath for breath. There is no other way in which to reach that person's rhythm'. To listen breath for breath: it is a beautiful and evocative phrase and it reminds us to listen for what goes unspoken but not necessarily unsaid. Reflecting on this makes me realize that Indigenous voices are completely absent from Stories of Love \& Hate as well as from the initial riots. Two tribes are fighting over land that was not theirs to begin with, for the word Cronulla derives from kurranulla, which means 'place of the pink sea shells' in the dialect of the area's Indigenous inhabitants, the Gwe-agal, a clan of the Dharawal tribe. This fact was acknowledged when the cast performed an excerpt of the play at the Museum of Contemporary Art in association with Aboriginal artist Fiona Foley's photographic series Nulla 4 Eva (2008).

This remount at the MCA was one of many, as Stories of Love \& Hate made its way from the margins to the mainstream, starting with short performances at the Sydney Writers' Festival (2008); the Transcultural Mappings conference at the University of Sydney (2008); Vitalstatistix, Adelaide (2011); finishing with a full production at the Sydney Theatre Company (2011) as part of its Education Program. There, almost two thousand schoolchildren saw it. ${ }^{61}$ Perhaps it is too much to hope that these children will learn how to listen, or to listen better, on the basis of having seen this show, but it is not too much to say that the arduous listening of Oades and her cast contrasts sharply with the profound lack of listening that lay at the heart of the Cronulla Riots. In repeating these stories of love and hate with such sensitivity and artistry, the performance provided Sydney audiences with an opportunity to rehear our fellow citizens and to rehearse new modes of listening and belonging. To recall and at the same time refute Studs Terkel, Stories of Love \& Hate became a theatre of both communication and communications.

NOTES

1 I wish to thank Roslyn Oades, for her generous assistance, and Helena Grehan, for her feedback on an earlier draft. I am also grateful to colleagues at PSi\#16, who heard a shorter version of this paper.

Anna Deavere Smith, Talk to Me: Travels in Media and Politics (New York: Anchor Books, 200o), p. 45. Ibid., p. 11.

4 Alan Read, Theatre, Intimacy \& Engagement: The Last Human Venue (Basingstoke: Palgrave Macmillan, 2008).

5 Nick Couldry, Why Voice Matters: Culture and Politics after Neoliberalism (London: Sage, 2010).

6 Ibid., pp. 1-2o.

7 Jodi Dean, Democracy and Other Neoliberal Fantasies: Communicative Capitalism and Left Politics (Durham, NC: Duke University Press, 2009), p. 24.

8 Ibid., p. 24 .

9 Recorded Delivery, www.recordeddelivery.net/about.html, accessed 10 November 2013; Roslyn Oades, 'Creating a Headphone-Verbatim Performance', in Paul Brown, ed., Verbatim: Staging Memory and 
Community (Sydney: Currency Press, 2010), pp. 84-7. See also Roslyn Oades, 'Headphone Verbatim and Audio Scripting', at www.roslynoades.com/Technique.html, accessed 11 November 2013. Derek Paget, "Verbatim Theatre": Oral History and Documentary Techniques', New Theatre Quarterly, 3, 12 (1987), pp. 317-36, here p. 317.

11 Oades, 'Creating', p. 84.

12 David Williams, 'All in the Re-telling', RealTime 70 (2005), p. 41, available at http://realtimearts.net/article/70/7994, accessed 28 March 2013.

13 Caroline Wake, 'Headphone Verbatim Theatre: Methods, Histories, Genres, Theories', New Theatre Quarterly, 29, 4 (2013), pp. 321-35.

14 Lucy Nevitt, 'Review of Theatre as Witness: Three Testimonial Plays from South Africa', Research in Drama Education, 13, 3 (2008), pp. 377-9, here p. 377; see also Mary Luckhurst, 'Verbatim Theatre, Media Relations and Ethics', in Mary Luckhurst and Nadine Holdsworth, eds., A Concise Companion to Contemporary British and Irish Drama (Oxford: Blackwell, 2008), pp. 200-22, here p. 215 .

15 With sincere thanks to the reviewer who suggested the term 'audio-cued performance'.

16 See Lib Taylor, 'Voice, Body, and the Transmission of the Real in Documentary Theatre', Contemporary Theatre Review, 23, 3 (2013), pp. 368-79.

17 Back to Back Theatre, small metal objects, available at http://backtobacktheatre.com/projects/show/small-metal-objects, accessed 12 November 2013.

18 Christopher Balme, 'Audio Theatre: The Mediatization of Theatrical Space', in Freda Chapple and Chiel Kattenbelt, eds., Intermediality in Theatre and Performance(Amsterdam: Rodopi, 2006), pp. 117-24.

19 Scott Poynting, Greg Noble, Paul Tabar and Jock Collins, Bin Laden in the Suburbs: Criminalising the Arab Other (Sydney: Sydney Institute of Criminology, 2004).

$20 \quad$ Macquarie Dictionary Online, accessed 28 December 2013.

21 David Marr, 'One-Way Radio Plays by Its Own Rules', Sydney Morning Herald, 13 December 2005, available at www.smh.com.au/news/national/oneway-radio-plays-by-its-own-rules/2005/12/12/1134236005956.html, accessed 28 March 2013.

22 Ibid.; Liz Jackson, 'Riot and Revenge', Four Corners, 13 March 2006, available at www.abc.net.au/4corners/content/2006/s1590953.htm, accessed 28 March 2013. If geoblocking is in place, see www.youtube.com/watch? $\mathrm{v}=$ KabOOwXUk-8, accessed 29 November 2013.

23 Stringa, 'Darkest Day for So-Called Patriotism: Boozed-up Crowd Erupts', St George \& Sutherland Shire Leader, 13 December 2005, p. 9.

24 This is a necessarily truncated version of events. For more detail and analysis, see Ben Cubby, 'The Australian Way', Griffith Review, 13 (2006), available at https://griffithreview.com/edition-13-the-next-big-thing/the-australian-way, accessed 28 March 2013, pp. 90-8; Gerard Goggin, 'SMS Riot: Transmitting Race on a Sydney Beach, December 2005', M/C Journal, 9, 1 (2006), available at http://journal.media-culture.org.au/o603/o2-goggin.php, accessed 28 March 2013; Scott Poynting, 'What Caused the Cronulla Riot', Race \& Class, 48, 1 (2006), pp. 85-92; and Greg Noble, ed. Lines in the Sand: The Cronulla Riots, Multiculturalism, and National Belonging (Sydney: Institute of Criminology 2009). Footage can be seen at Australian Broadcasting Corporation, 'Communities Clash Violently at Cronulla: 8o Days That Changed Our Lives', available at www.abc.net.au/archives/8odays/stories/2012/01/19/3412161.htm, accessed 28 March 2013. Poynting, 'What Caused the Cronulla Riot', p. 85.

26 Geoffrey Braham Levey and A. Dirk Moses, “"The Muslims Are Our Misfortune!” in Noble, Lines in the Sand, pp. 95-110, here pp. 98-102.

27 Cubby, 'The Australian Way', p. 94.

28 Others include Noelle Janaczewska's This Territory (2007), Laura Scrivano's The Cronulla Project (2007), Big hART's Junk Theory (2007), David Brown's Boy Called Flag (2007), Reg Cribb's UnAustralia (2007), and Suzie Miller's All the Blood \& All the Water (2008). 
29 For more information on Urban Theatre Projects see www.urbantheatre.com.au, accessed 28 March 2013; for more information on Bankstown Youth Development Service see www.byds.org.au, accessed 28 March 2013. For more information about Roslyn Oades see www.roslynoades.com, accessed 12 November 2013. Oades states, 'all the people interviewed were directly involved in or affected by the riots. I sought out passionate, open people and each interview began with a discussion of the "love of your life" and concluded with a discussion of personal experiences of the riot and its aftermath. Subjects were also asked to nominate and, if possible, sing their favourite love song'. Roslyn Oades, personal communication with the author, 23 November 2012. Part of the following description first appeared in my review of the play for RealTime arts magazine. Caroline Wake, 'Learning to Listen: UTP's Stories of Love \& Hate', RealTime, 89 (2009), p. 36, available at www.realtimearts.net/article/89/9352, accessed 28 March 2013.

34 Roslyn Oades, Stories of Love \& Hate, unpublished script, 2008, p. 7. Subsequent references will be given in-text. While Oades was happy to share the transcript with me, she also cautioned that the transcript 'it is not the actual "script" of the show, which exists as audio only, and was never distributed to the actors in paper form'. Roslyn Oades, personal communication with the author, 14 November 2012. John Tebbutt, 'The Object of Listening', Continuum: Journal of Media \& Cultural Studies, 23, 4 (2009), pp. 549-59, here p. 552.

36 Shoshana Felman and Dori Laub, Testimony: Crises of Witnessing in Literature, Psychoanalysis, and History (New York: Routledge, 1992), p. 58.

37 Julie Salverson, 'Performing Emergency: Witnessing, Popular Theatre, and the Lie of the Literal', Theatre Topics, 6, 2 (1996), pp. 181-91, here p. 188; Julie Salverson, 'The Art of Witness in Popular Theatre', Canadian Theatre Review, 90 (1997), pp. 36-9, here p. 38.

38 Julie Salverson, 'Spoken and Unspoken: When Theatre Meets Labour', Canadian Theatre Review, 99 (1999), pp. 28-30, here p. 30.

39 Justine Lloyd, 'The Listening Cure', Continuum: Journal of Media \& Cultural Studies, 23, 4 (2009), pp. 477-87, here p. 482.

40 Urban Theatre Projects, Stories of Love \& Hate: Program (Sydney: Urban Theatre Projects, 2008), p. 3.

41 Jill Dolan, Utopia in Performance: Finding Hope at the Theater (Ann Arbor: University of Michigan Press, 2005), p. 129.

42 Ibid., p. 129.

43 Ibid., p. 127.

44 Freddie Rokem, Performing History: Theatrical Representations of the Past in Contemporary Theatre (Iowa City: University of Iowa Press, 2000), p. 204.

45 Ibid., pp. 203-4.

46 Krista Ratcliffe, Rhetorical Listening: Identification, Gender, Whiteness (Carbondale: Southern Illinois University Press, 2005), p. 104.

47 Ibid., pp. 104-5, original ellipses.

48 Ibid., p. 105.

49 Ibid., p. 107.

50 Ibid., p. 107.

51 Ibid., p. 105.

52 Tanja Dreher, 'Eavesdropping with Permission: The Politics of Listening for Safer Speaking Spaces', borderlands, 8, 1 (2009), pp. 1-21, here p. 1, available at www.borderlands.net.au/vol8no1_2009/dreher_eavesdropping.htm, accessed 28 March 2013.

53 Oades explains, 'I would not offer the option to withdraw the interview once it had been incorporated into the [devising] process. I would, however, always be open to ensuring a participant was completely 
anonymous if preferred (i.e. name not mentioned in the performance or program)'. Roslyn Oades, personal communication with the author, 23 November 2012.

55 Iain Chambers, Migrancy, Culture, Identity (London: Routledge, 1994), p. 49.

56 Paget, 'Verbatim Theatre', pp. 317, 326.

57 Nadyat El-Gawley and Penny O’Donnell, 'Listening, Journalism and Community Voices: Nadyat El Gawley in Conversation with Penny O’Donnell', Continuum: Journal of Media \& Cultural Studies, 23, 4 (2009), pp. 519-23, here pp. 520-2.

58 Lloyd, 'The Listening Cure', p. 479.

59 Alice Rayner, 'The Audience: Subjectivity, Community and the Ethics of Listening', Journal of Dramatic Theory and Criticism, 7, 2 (1993), pp. 3-24.

$60 \quad$ Lloyd, 'The Listening Cure', p. 478.

61 Sydney Theatre Company, Annual Report 2011 (Sydney: Sydney Theatre Company, 2011), p. 32, available at www.sydneytheatre.com.au/media/466595/ar2011_download.pdf, accessed 14 November 2012.

CAROLINE WAKE (c.wake@unsw.edu.au) is a Postdoctoral Fellow at the Centre for Modernism Studies in Australia at the University of New South Wales. Her research examines responses to and representations of refugees and asylum seekers in performance and visual culture; theatres of the real, including testimonial, tribunal and documentary theatre; and the documentation of performance itself, especially online. 